\title{
CONFORMATIONAL ANALYSIS OF THIAZOLE-5-CARBOXYLIC ACID USING DFT/TD-DFT METHODS
}

\author{
Nihal KUŞ \\ Department of Physics, Science Faculty, Eskisehir Technical University, 26470, Eskisehir, Turkey
}

\begin{abstract}
In this work, structures of the conformers of the thiazole-5-carboxylic acid (T5CA) were studied using density functional theory (DFT) with B3LYP/6-311++G(d,p) level of approximation. From calculations of the potential energy distribution depending on the orientation of the carboxylic group $(\mathrm{C}-\mathrm{C}-\mathrm{OH}$ and $\mathrm{O}=\mathrm{C}-\mathrm{OH})$ attached to the five-membered heterocyclic ring, four conformers were found at minimum energy. Considering that the relative energy in the most stable structure is zero. The relative energies of the other conformations were found to be about $0.14,27.11,29.84 \mathrm{~kJ}$ mol-1, respectively. It was found that the carboxylic acid group of the T5CA_3 and 4 were not planar, while T5CA_1 and T5CA_2 were planar. Stabilization and donoracceptor orbital interaction energies were calculated for all conformations and orbitals were plotted using natural bond orbital analysis (NBO) method. The excited state energies were calculated and graphed using Time-Dependent Density Functional Theory (TD-DFT) calculations. The singlet state energies were tabulated for all conformations and it was seen that the most stable form with the highest oscillator strength was at the second singlet state (S2). In addition, HOMO-LUMO energy gaps were calculated and electrostatic potential surface maps were drawn for all conformations.
\end{abstract}

Keywords: Thiazole-5-carboxylic acid (T5CA), DFT/ TD-DFT, NBO, HOMO-LUMO energy

\section{INTRODUCTION}

Carboxylic acids contain carboxyl functional groups $(-\mathrm{COOH})$ and carbonyl groups $(\mathrm{C}=\mathrm{O})$ with a hydroxyl $(\mathrm{O}-\mathrm{H})$ attached to the same carbon atom in their structures. Since the electronegativity of oxygen is higher than that of carbon and hydrogen, the oxygen atoms in the carboxyl group are partially negative and the carbon and hydrogen atoms are partially positively charged. It has a strong dipole bond between carbon and oxygen in the carbonyl group. Many studies have been carried out in recent years on molecules formed by carboxylic acid groups attached to thiazole and isothiazole rings. One of the study was done by Kaur et al. using thiazole-5-carboxylic acid (T5CA). They proportionally synthesized 22 different compounds of T5CA derivatives and also characterized all the compounds by $1 \mathrm{H}$ and $13 \mathrm{C} \mathrm{NMR}$. After all these studies, they discussed the results of spectrophotometric tests against xanthine oxidase enzyme [1]. Fausto et al. (2016) studied with thiazole-2-carboxylic acid. They trapped the molecule in argon and nitrogen noble gases and investigated the conformational changes of the molecule by near infrared and UV lights using spectroscopic methods [2]. Thiazoline and thiazole ester compounds were synthesized and their thermal properties were studied [3]. Five new molecular complexes were successfully synthesized using thiazole-4-carboxylic acid as the ligand and, these new structures were characterized by single crystal X-ray diffraction [4]. Using a variety of experimental and theoretical techniques, Li et al. (1993) determined the crystalline molecular structure of isothiazofurine using single crystal X-ray diffraction techniques and 1H NMR. They also confirmed their results theoretically [5]. Bonnel et al. (2016) re-investigated the structures of thiazole-based-peptide folders with FT-IR and NMR [6].

In this study, conformational structures of T5CA were investigated by computational methods. Stabilization energies and donor acceptor orbital interactions were calculated by natural bond orbital (NBO) analysis method. Using time dependent density function theory (TD-DFT) method, excitation

*Corresponding Author: nkus@eskisehir.edu.tr

Received: 30.10.2020 Published: 27.11.2020 
energies were calculated and singlet and triplet level energies were found. HOMO-LUMO energy gap of the T5CA conformations were calculated and the effects of electrostatic potentials were drawn.

\section{THEORETICAL CALCULATIONS}

Quantum chemical calculations for T5CA were done using the Gaussian 09 program [7]. The equilibrium geometries in the ground state of the molecule are optimized together $6-311++\mathrm{G}(\mathrm{d}, \mathrm{p})$ basis set of density function theory (DFT) and the B3LYP functionality. This approach is a very powerful technique for analyzing the structure and conformation of the studying molecule. The relative stability of the conformations was calculated using the NBO analysis, developed by Weinhold and the working group and applicable in the Gaussian 09 program, using the NBO 3.1 program [8]. The energies of the excited states were calculated using the B3LYP/6-311++G(d,p) approach of the TD-DFT [9, 10]. Molecular electrostatic potential (MEP) surfaces of the positions of the positive and negative charges of the conformations analyzed by drawing them.

\section{RESULTS AND DISCUSSION}

T5CA $\left(\mathrm{C}_{4} \mathrm{H}_{3} \mathrm{NO}_{2} \mathrm{~S}\right)$ is a 5-atom heterocyclic ring structure. The interaction between the $\mathrm{OH}$ group and the ring-bound nitrogen should be weaker than for a six-atom heterocyclic structure, e.g. pyridine-2carboxylic acid [11]. The present study has also set an example for this situation.

Table 1. Optimized relative electronic, electronic + zero point vibrational and Gibbs energies $\left(\mathrm{kJ} \mathrm{mol}^{-1}\right)$ for T5CA conformers using DFT method with B3LYP/6-311++G(d,p)level.

\begin{tabular}{|llll|}
\hline Form & $\Delta \mathrm{E}(\mathrm{RB} 3 \mathrm{LYP})$ & $\Delta(\mathrm{E}+\mathrm{ZPV})$ & $\Delta \mathrm{G}$ \\
\hline T5CA_1 & 0 & 0 & 0 \\
\hline T5CA_2 & 0.111951 & 0.141777 & 0.110271 \\
\hline T5CA_3 & 28.31523 & 27.11091 & 25.73253 \\
\hline T5CA_4 & 31.44267 & 29.83881 & 28.03509 \\
\hline
\end{tabular}

Rotatable bonds are shown in Figure 1 with adopted atom numbers and 4 different conformers have been obtained using potential energy distribution calculations. Calculated Relative Energies of T5CA conformers using DFT/B3LYP/6-311++G(d,p) between T5CA_1 and 4 were given in Table 1 . As can be seen from Table 1, the most stable structure is T5CA_1, and the calculated $\Delta(\mathrm{E}+\mathrm{ZPV})$ value of the other conformations (together with the zero point energy value) were $0.14,27.11,29.84 \mathrm{~kJ} \mathrm{~mol}^{-1}$, respectively. It was found that the 1 st and 2 nd conformations were planar after optimizing, but the 3 rd and 4th conformers were not.

Potential energy graph of the T5CA_1 conformer obtained by rotating the $\mathrm{C} 1-\mathrm{C} 5-\mathrm{C} 8-\mathrm{O} 10$ dihedral angle in $30^{\circ}$ steps is given in Figure 2 (a). The 0 and $180^{\circ}$ of this angle show the most stable cases of 1 and 2 conformers. In addition, the form in the transition state was observed as $90^{\circ}$ and the barrier energy was calculated as 31.7 , while it was only $31.6 \mathrm{~kJ} \mathrm{~mol}^{-1}$ at $180^{\circ}$. The $\Delta \mathrm{E}$ electronic energy difference between conformers T5CA_1 and T5CA_2 is only $0.11 \mathrm{~kJ} \mathrm{~mol}^{-1}$. Together with the zero point energy, this value is $0.14 \mathrm{~kJ} \mathrm{~mol}^{-1}$. This small value was not shown in the Figure 1(a). 

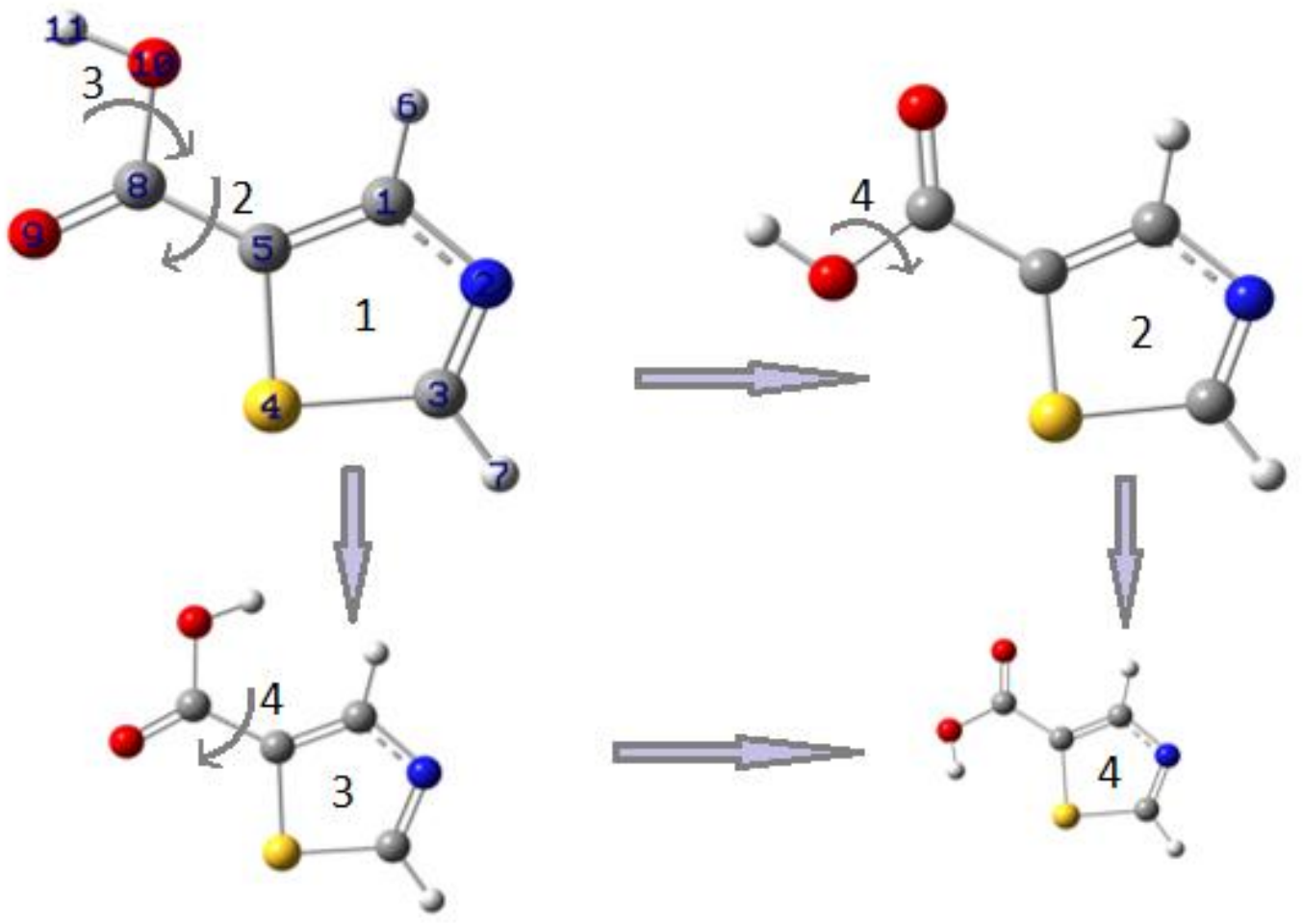

Figure 1. Scheme of T5CA conformers with adopted atom numbers.

Figure 2 (b) shows that the formation of the T5CA_3 from the T5CA_1, which is the most stable structure, occurs with the rotation of the dihedral angle $\mathrm{O} 9=\mathrm{C} 8-\mathrm{O} 10-\mathrm{C} 11$. The barrier energy generated for the conversion from T5CA_1 to T5CA_3 is $48.4 \mathrm{~kJ} \mathrm{~mol}^{-1}$, in reverse case this value is $20.1 \mathrm{~kJ} \mathrm{~mol}^{-}$ ${ }^{1}$. The transformation of T5CA_2 form, which is in the second stable state, to the form T5CA_4, occurred by 180 o rotation of the $\mathrm{O} 9=\mathrm{C} 8-\mathrm{O} 10-\mathrm{H} 11$ dihedral angle. This situation is shown in Figure $2 \mathrm{c}$. In this case, the barrier energy is $51.1 \mathrm{kJmol}^{-1}$ and in the reverse case it is $19.7 \mathrm{~kJ} \mathrm{~mol}^{-1}$. For the formation of the T5CA_4 from the T5CA_3, the dihedral angle $\mathrm{C} 1-\mathrm{C} 5-\mathrm{C} 8-\mathrm{O} 10$ had to rotate. The barrier energy created by $180^{\circ}$ rotation of this angle was $18.1 \mathrm{~kJ} \mathrm{~mol}^{-1}$, and $15 \mathrm{~kJ} \mathrm{~mol}^{-1}$ in the reverse case.
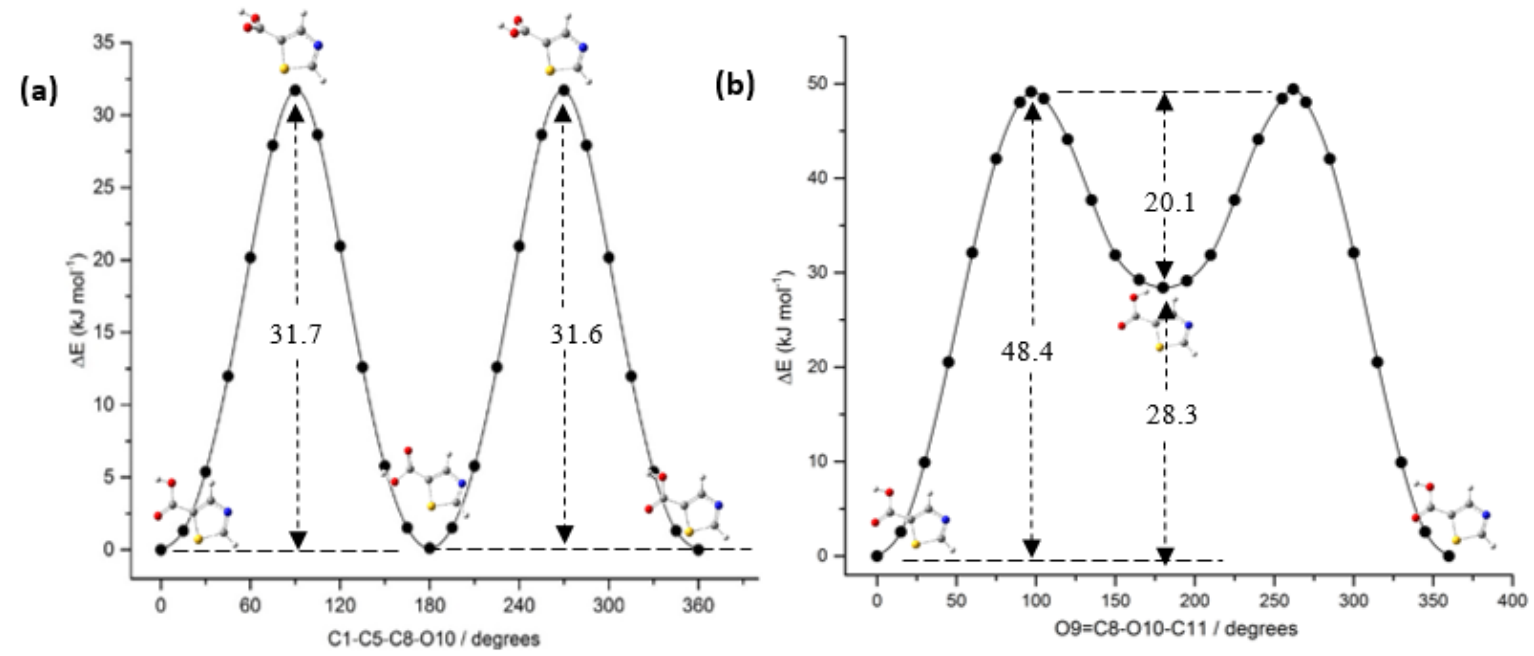

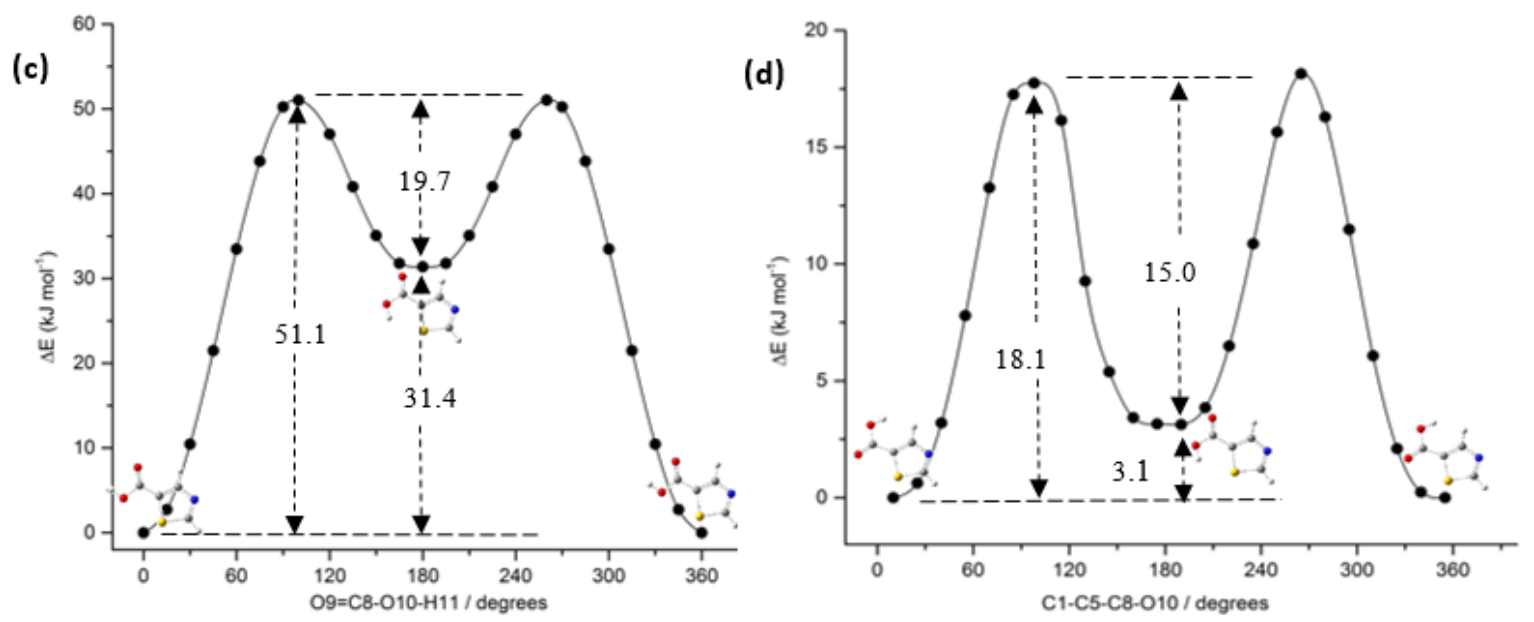

Figure 2. Rotations around the (a) $\mathrm{C}-\mathrm{C}$ bond enabling the formation of the T5CA_1 to T5CA_2, (b) $\mathrm{C}-\mathrm{O}$ bond enabling the formation of the T5CA_1 to T5CA_3, (c) C-O bond enabling the formation of the T5CA_2 to T5CA_4, (d) C-C bond enabling the formation of the T5CA_3 to T5CA_4

In previous studies on the tiazole-2-carboxcylic acid molecule, the MP2/6-311++G(3df,3pd) method was used to calculate the barrier energies and the barrier height for the II $\rightarrow$ I transformation (in our study formation of the T5CA_2 to T5CA_4) was found to be approximately $46 \mathrm{~kJ} \mathrm{~mol}^{-1}$ and note that the $\mathrm{N}$ and $\mathrm{S}$ atoms were numbered 1 and 3 on both sides of the carboxylic acid group [2].

Stabilization energies were calculated from the Fock matrix equation [12], and this equation is given below (Eq.1). Energies greater than 10 percent were taken into account. These values and donoracceptor orbital interactions are given in Table 2.

$$
E(2)=\Delta E_{i j}=q_{i} \frac{F_{i j}^{2}}{\varepsilon_{j}-\varepsilon_{i}}
$$

In the Eq.1, the matrix element between the $i$ and $j \mathrm{NBO}$ orbitals is given by $F_{i j}$. $q_{i}$ is the occupancy of the donating orbital. The energies of acceptor and donor NBOs are shown as $\varepsilon_{i}$ and $\varepsilon_{j}$.

Table 2. Stabilization energies of T5CA conformers (conformers 1, 2, 3 and 4) for NBO pairs selected by second order perturbation theory analysis calculated from B3LYP/6-311++G(d,p) level of theory.

\begin{tabular}{|l|l|l|r|r|r|}
\hline T5CA_1 & Donor NBO $(i)$ & Acceptor NBO $(j)$ & $\begin{array}{c}\mathrm{E}(2) \\
\mathrm{kJ} \mathrm{mol}^{-1}\end{array}$ & $\begin{array}{c}\mathrm{E}(j)-\mathrm{E}(i) \\
\text { a.u. }\end{array}$ & $\begin{array}{c}\mathrm{F}(i, j) \\
\text { a.u. }\end{array}$ \\
\hline$\pi(\mathrm{C} 1-\mathrm{C} 5)$ & $\pi^{*}(\mathrm{~N} 2-\mathrm{C} 3)$ & 49.08 & 0.27 & 0.053 \\
\hline$\pi(\mathrm{C} 1-\mathrm{C} 5)$ & $\pi^{*}(\mathrm{C} 8-\mathrm{O} 9)$ & 90.42 & 0.29 & 0.073 \\
\hline$\pi(\mathrm{N} 2-\mathrm{C} 3)$ & $\pi^{*}(\mathrm{C} 1-\mathrm{C} 5)$ & 87.07 & 0.34 & 0.078 \\
\hline $\mathrm{LP}(1) \mathrm{N} 2$ & $\sigma^{*}(\mathrm{C} 3-\mathrm{S} 4)$ & 57.99 & 0.57 & 0.080 \\
\hline LP(2)S4 & $\pi^{*}(\mathrm{C} 1-\mathrm{C} 5)$ & 82.05 & 0.26 & 0.066 \\
\hline $\mathrm{LP}(2) \mathrm{S} 4$ & $\pi^{*}(\mathrm{~N} 2-\mathrm{C} 3)$ & 127.24 & 0.24 & 0.078 \\
\hline $\mathrm{LP}(1) \mathrm{O} 9$ & $\mathrm{Ry}(1) \mathrm{C} 8$ & 65.02 & 1.81 & 0.150 \\
\hline $\mathrm{LP}(2) \mathrm{O} 9$ & $\sigma^{*}(\mathrm{C} 5-\mathrm{C} 8)$ & 71.17 & 0.70 & 0.100 \\
\hline LP(2)O9 & $\sigma^{*}(\mathrm{C} 8-\mathrm{O} 10)$ & 140.04 & 0.60 & 0.129 \\
\hline $\mathbf{A}) \mathbf{L P}(2) \mathbf{O 1 0}$ & $\pi^{*}(\mathbf{C 8}-\mathbf{O} 9)$ & $\mathbf{1 7 8 . 3 2}$ & $\mathbf{0 . 3 4}$ & $\mathbf{0 . 1 1 1}$ \\
\hline
\end{tabular}

A) Orbital interaction shown in Fig. 3-A. 
Kuş / Eskişehir Technical Univ. J. of Sci. and Tech. A - Appl. Sci. and Eng. Vol. $21-2020$

T5CA_2

\begin{tabular}{|l|l|r|r|r|}
\hline Donor NBO $(i)$ & Acceptor NBO $(j)$ & $\begin{array}{c}\mathrm{E}(2) \\
\mathrm{kJ} \mathrm{mol}^{-1}\end{array}$ & $\begin{array}{c}\mathrm{E}(j)-\mathrm{E}(i) \\
\text { a.u. }\end{array}$ & $\begin{array}{c}\mathrm{F}(i, j) \\
\text { a.u. }\end{array}$ \\
\hline$\pi(\mathrm{C} 1-\mathrm{C} 5)$ & $\pi^{*}(\mathrm{~N} 2-\mathrm{C} 3)$ & 49.87 & 0.27 & 0.053 \\
\hline$\pi(\mathrm{C} 1-\mathrm{C} 5)$ & $\pi^{*}(\mathrm{C} 8-\mathrm{O} 9)$ & 89.54 & 0.29 & 0.072 \\
\hline$\pi(\mathrm{N} 2-\mathrm{C} 3)$ & $\pi^{*}(\mathrm{C} 1-\mathrm{C} 5)$ & 87.40 & 0.34 & 0.078 \\
\hline $\mathrm{LP}(1) \mathrm{N} 2$ & $\pi^{*}(\mathrm{C} 3-\mathrm{S} 4)$ & 58.70 & 0.57 & 0.080 \\
\hline $\mathrm{LP}(2) \mathrm{S} 4$ & $\pi^{*}(\mathrm{C} 1-\mathrm{C} 5)$ & 80.88 & 0.27 & 0.066 \\
\hline $\mathrm{LP}(2) \mathrm{S} 4$ & $\pi^{*}(\mathrm{~N} 2-\mathrm{C} 3)$ & 125.35 & 0.24 & 0.078 \\
\hline $\mathrm{LP}(1) \mathrm{O} 9$ & $\mathrm{Ry}(1) \mathrm{C} 8$ & 67.20 & 1.79 & 0.151 \\
\hline $\mathrm{LP}(2) \mathrm{O} 9$ & $\sigma^{*}(\mathrm{C} 5-\mathrm{C} 8)$ & 72.51 & 0.70 & 0.101 \\
\hline LP(2)O9 & $\sigma^{*}(\mathrm{C} 8-\mathrm{O} 10)$ & 138.99 & 0.60 & 0.128 \\
\hline${ }^{B} \mathbf{L P}(\mathbf{2}) \mathbf{O 1 0}$ & $\pi^{*}(\mathbf{C 8}-\mathbf{O} 9)$ & $\mathbf{1 7 8 . 5 3}$ & $\mathbf{0 . 3 5}$ & $\mathbf{0 . 1 1 1}$ \\
\hline
\end{tabular}

B) Orbital interaction shown in Fig. 3-B.

T5CA_3

\begin{tabular}{|c|c|c|c|c|}
\hline Donor NBO $(i)$ & Acceptor NBO $(j)$ & $\begin{array}{c}\mathrm{E}(2) \\
\mathrm{kJ} \mathrm{mol}^{-1}\end{array}$ & $\begin{array}{c}\mathrm{E}(j)-\mathrm{E}(i) \\
\text { a.u. }\end{array}$ & $\begin{array}{l}\mathrm{F}(i, j) \\
\text { a.u. }\end{array}$ \\
\hline$\pi(\mathrm{C} 1-\mathrm{C} 5)$ & $\pi^{*}(\mathrm{~N} 2-\mathrm{C} 3)$ & 48.49 & 0.28 & 0.053 \\
\hline$\pi(\mathrm{C} 1-\mathrm{C} 5)$ & $\pi^{*}(\mathrm{C} 8-\mathrm{O} 9)$ & 75.94 & 0.32 & 0.069 \\
\hline$\pi(\mathrm{N} 2-\mathrm{C} 3)$ & $\pi *(\mathrm{C} 1-\mathrm{C} 5)$ & 85.90 & 0.33 & 0.077 \\
\hline LP(1)N2 & $\sigma^{*}(\mathrm{C} 3-\mathrm{S} 4)$ & 56.74 & 0.57 & 0.079 \\
\hline LP(2)S4 & $\pi *(\mathrm{C} 1-\mathrm{C} 5)$ & 86.19 & 0.26 & 0.067 \\
\hline $\mathrm{LP}(2) \mathrm{S} 4$ & $\pi *(\mathrm{~N} 2-\mathrm{C} 3$ & 128.11 & 0.24 & 0.078 \\
\hline $\mathrm{LP}(1) \mathrm{O} 9$ & Ry*(1)C8 & 61.09 & 1.83 & 0.146 \\
\hline $\mathrm{LP}(2) \mathrm{O} 9$ & $\sigma^{*}(\mathrm{C} 5-\mathrm{C} 8)$ & 74.98 & 0.67 & 0.100 \\
\hline $\mathrm{LP}(2) \mathrm{O} 9$ & $\sigma^{*}(\mathrm{C} 8-\mathrm{O} 10)$ & 138.95 & 0.60 & 0.128 \\
\hline${ }^{C}$ LP(2)O10 & $\pi^{*}(\mathrm{C} 8-09)$ & 163.89 & 0.35 & 0.107 \\
\hline
\end{tabular}

C) Orbital interaction shown in Fig. 3-C.

T5CA_4

\begin{tabular}{|l|l|r|r|r|}
\hline Donor NBO $(i)$ & Acceptor NBO $(j)$ & $\begin{array}{c}\mathrm{E}(2) \\
\mathrm{kJ} \mathrm{mol}^{-1}\end{array}$ & $\begin{array}{c}\mathrm{E}(j)-\mathrm{E}(i) \\
\text { a.u. }\end{array}$ & $\begin{array}{c}\mathrm{F}(i, j) \\
\text { a.u. }\end{array}$ \\
\hline$\pi(\mathrm{C} 1-\mathrm{C} 5)$ & $\pi^{*}(\mathrm{~N} 2-\mathrm{C} 3)$ & 51.84 & 0.27 & 0.054 \\
\hline$\pi(\mathrm{C} 1-\mathrm{C} 5)$ & $\pi^{*}(\mathrm{C} 8-\mathrm{O} 9)$ & 78.70 & 0.31 & 0.069 \\
\hline$\pi(\mathrm{N} 2-\mathrm{C} 3)$ & $\pi^{*}(\mathrm{C} 1-\mathrm{C} 5)$ & 85.10 & 0.34 & 0.077 \\
\hline $\mathrm{LP}(1) \mathrm{N} 2$ & $\sigma^{*}(\mathrm{C} 3-\mathrm{S} 4)$ & 63.14 & 0.55 & 0.082 \\
\hline $\mathrm{LP}(2) \mathrm{S} 4$ & $\pi^{*}(\mathrm{C} 1-\mathrm{C} 5)$ & 78.20 & 0.27 & 0.066 \\
\hline $\mathrm{LP}(2) \mathrm{S} 4$ & $\pi^{*}(\mathrm{~N} 2-\mathrm{C} 3)$ & 115.98 & 0.25 & 0.076 \\
\hline $\mathrm{LP}(1) \mathrm{O} 9$ & $\mathrm{Ry}^{*}(1) \mathrm{C} 8$ & 67.91 & 1.79 & 0.152 \\
\hline $\mathrm{LP}(2) \mathrm{O} 9$ & $\sigma^{*}(\mathrm{C} 5-\mathrm{C} 8)$ & 76.65 & 0.67 & 0.101 \\
\hline LP(2)O9 & $\sigma^{*}(\mathrm{C} 8-\mathrm{O} 10)$ & 137.53 & 0.60 & 0.127 \\
\hline DLP(2)O10 & $\pi^{*}(\mathbf{C 8}-\mathbf{0 9})$ & $\mathbf{1 6 9 . 3 3}$ & $\mathbf{0 . 3 5}$ & $\mathbf{0 . 1 0 8}$ \\
\hline
\end{tabular}

D) Orbital interaction shown in Fig. 3-D.

The highest stabilization energy for all conformers was seen in the interactions between LP(2)O and $\pi^{*}(\mathrm{C} 8-\mathrm{O} 9)$ orbitals. This amount of energy is about $178 \mathrm{~kJ} \mathrm{~mol}^{-1}$ for T5CA_1 and 2 conformers and slightly lower for T5CA_3 and 4 conformers (ca. 164 and $169 \mathrm{~kJ} \mathrm{~mol}^{-1}$, respectively). 
Kuş / Eskişehir Technical Univ. J. of Sci. and Tech. A-Appl. Sci. and Eng. Vol. $21-2020$
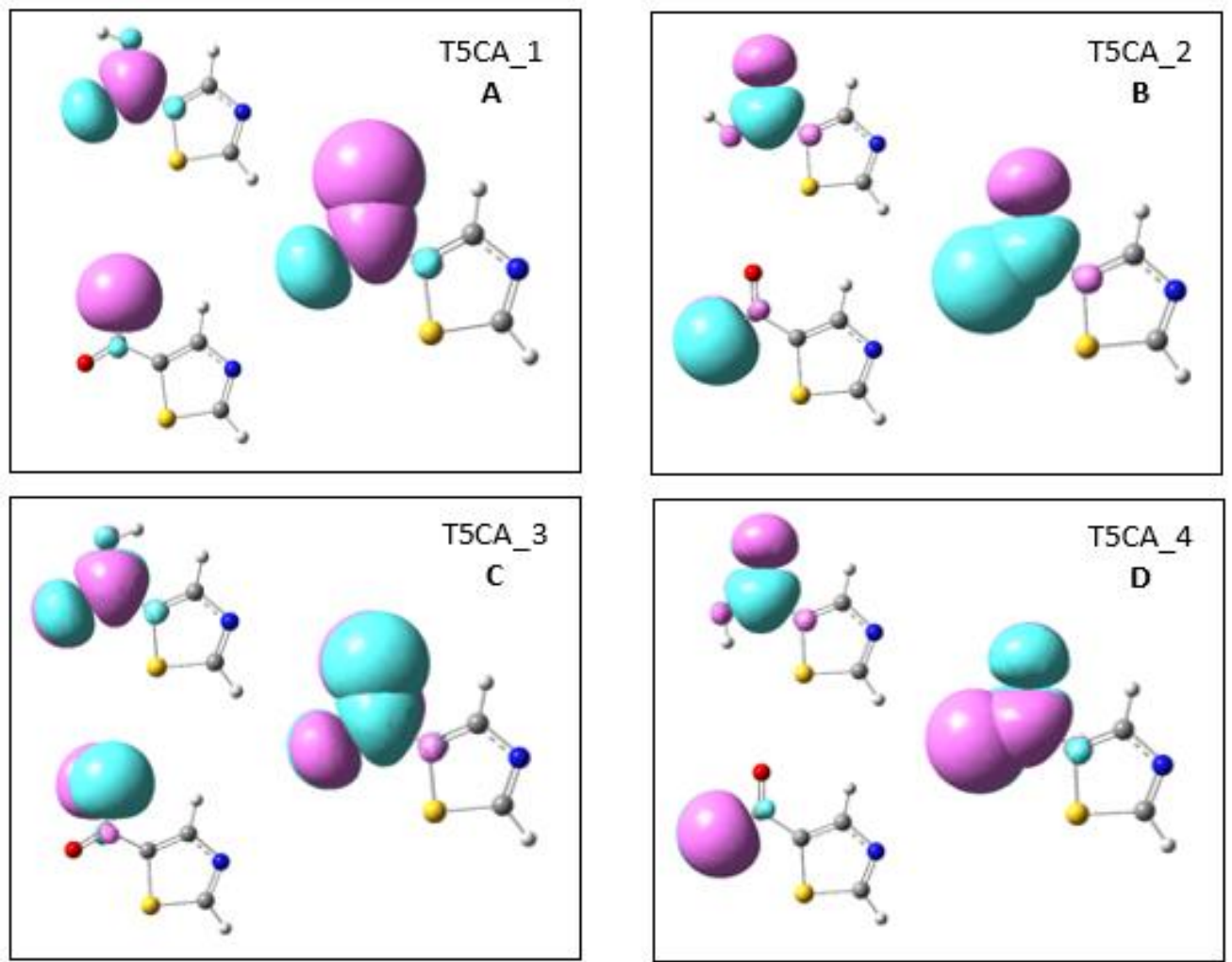

Figure 3. Orbital interaction of higher stabilization energies for conformers of T5CA

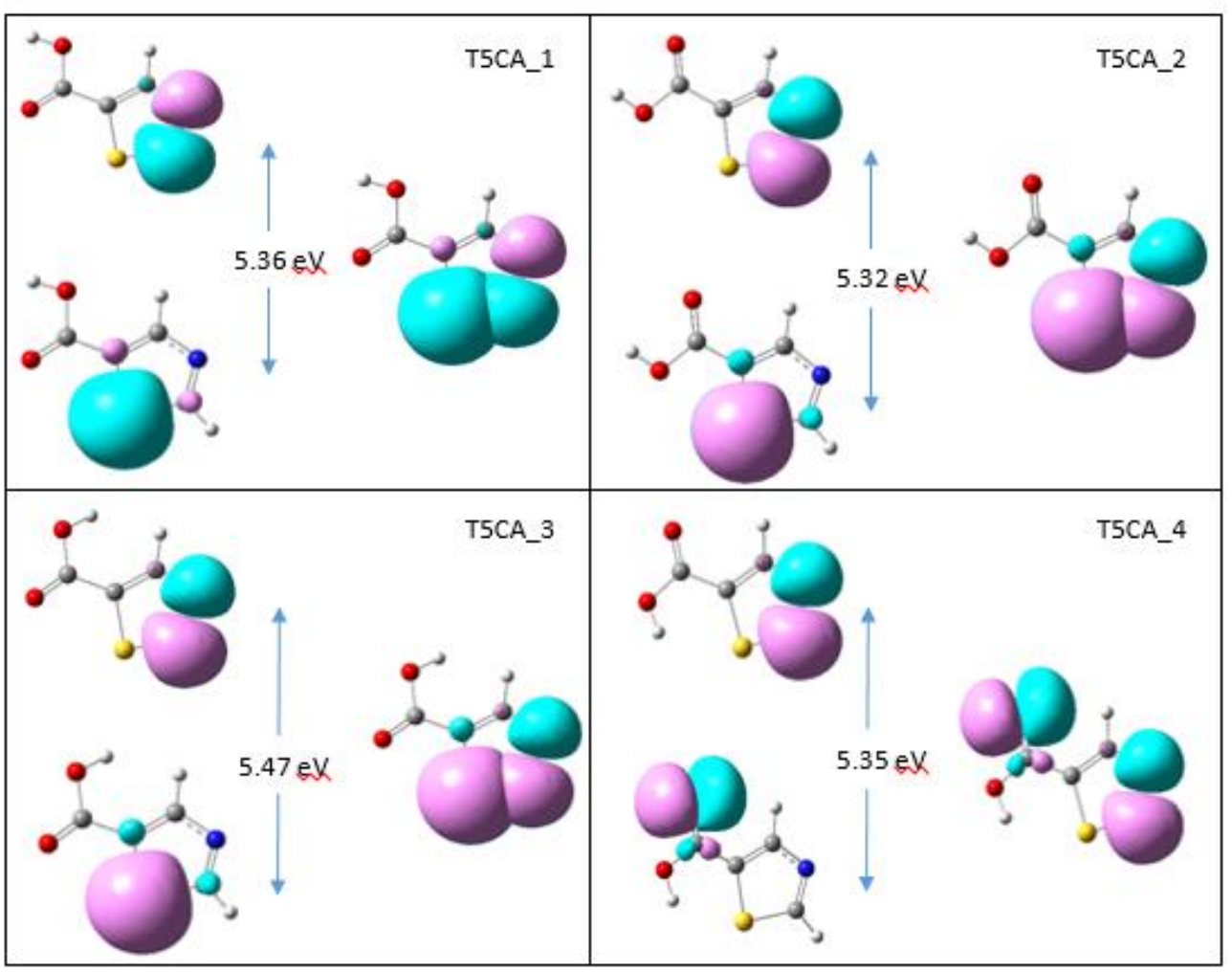

Figure 4. HOMO-LUMO difference energies of T5CA conformers calculated by NBO method 
HOMO-LUMO energy diagrams of all conformers of T5CA are given in Figure 4 according to NBO results and these energy values were calculated as 5.36, 5.32, 5.47 and $5.35 \mathrm{eV}$, respectively. The HOMO-LUMO orbital interactions of the T5CA_1, 2 and 3 conformers were observed between the lone pair $\mathrm{S}$ and $\pi^{*}(\mathrm{C}-\mathrm{N})$ in the thiazole ring, while the orbital interaction of the 4th conformer was between lone pair $\mathrm{O} 9$ in the carboxyl group and $\pi^{*}(\mathrm{C}-\mathrm{N})$ in the ring. In fact, it would not be right to mention about the HOMO-LUMO interaction for the conformer 4. As can be seen from the figure, there is no interaction between these two orbitals.

In a study, Fausto et al. (2016) observed the conformational changes II $\rightarrow$ I (in our study $1 \rightarrow 3$ ) irradiating the T2CA molecule, which they trapped in argon and nitrogen gases at very low temperatures, and observed these conformers as a result of excitation with an energy of 300 or $305 \mathrm{~nm}$. If such an experiment is planned, it is thought that the same change from T5CA_1 to 3 may occur when it irradiates with UV excitations about $\lambda>240 \mathrm{~nm}$, according to TD-DFT results (Figure 5).
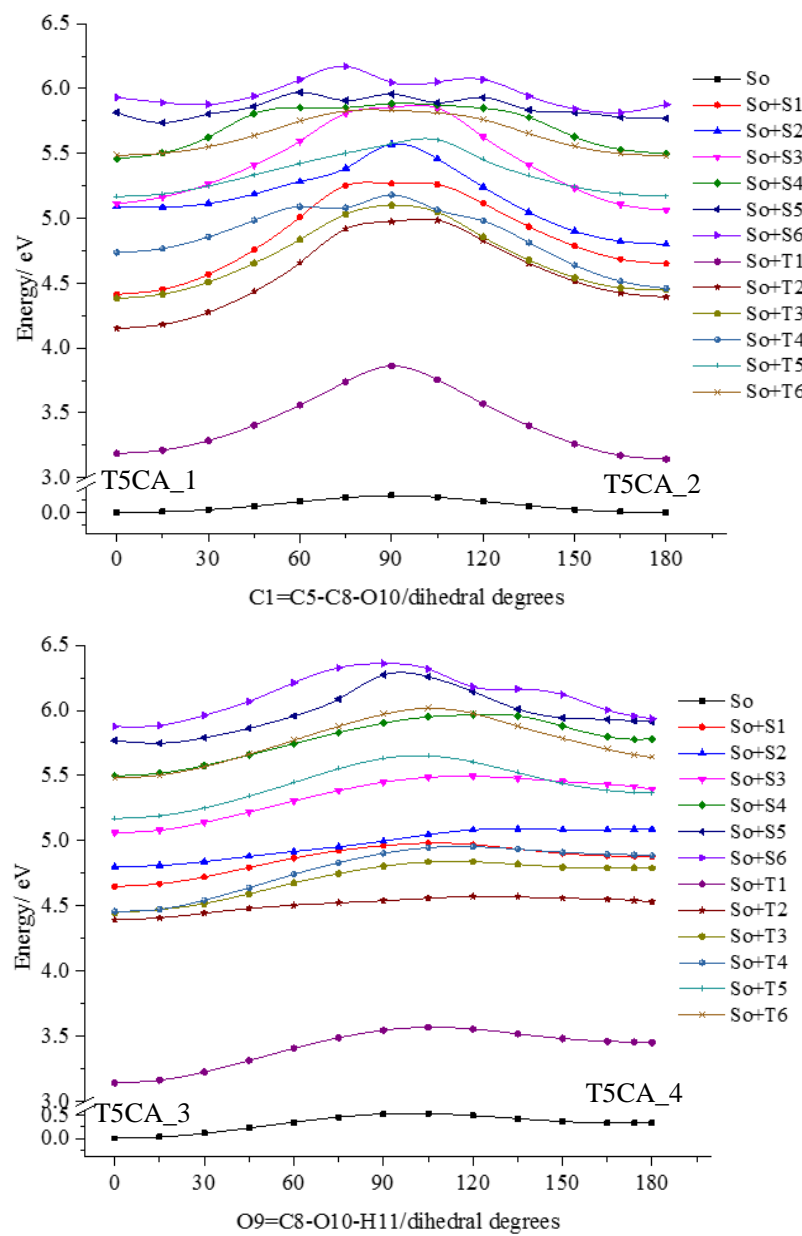
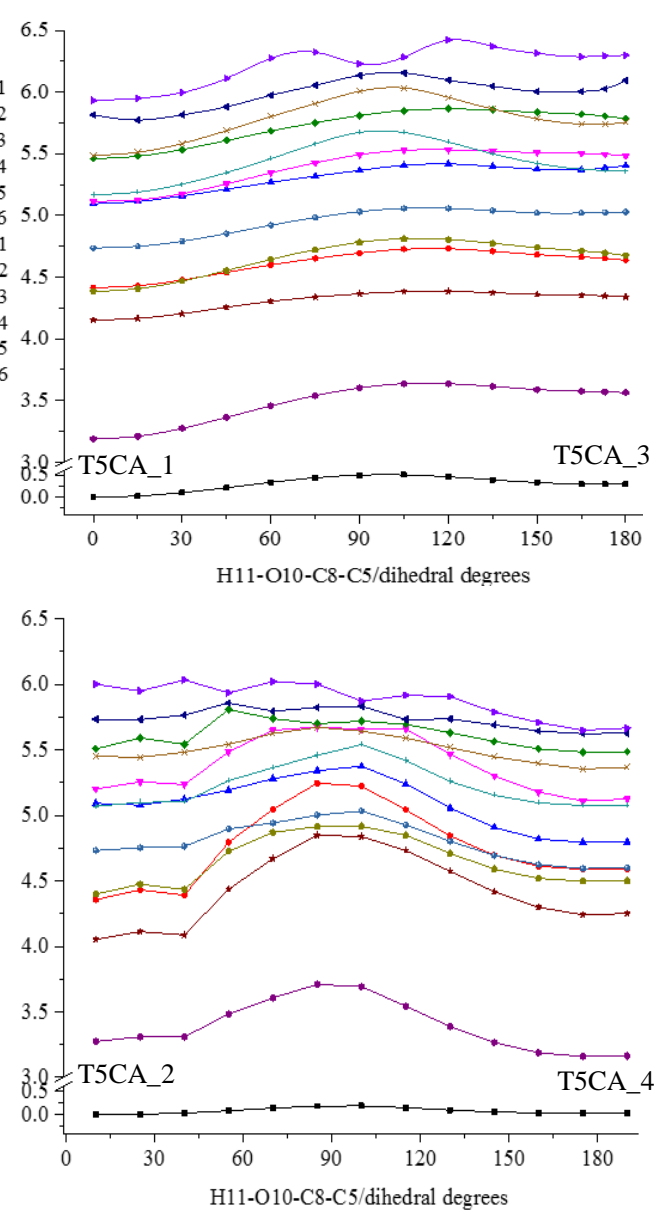

Figure 5. TD-DFT profiles of T5CA calculated by B3LYP/6-311++G(d,p) level of theory using rotation of carboxylic acid group. (y-axis break).

Singlet states, transition types and percentages, oscillator strengths and excitation energies for T5CA conformers are given in Table 3 . The values with the highest oscillator strength are indicative of the greatest absorption probability. It also indicates an excess of quantum mechanical quantities. This is also known as the transition dipole moment. The highest oscillator strength was observed in T5CA_1 conformer in S2 singlet state with 0.2039 . 
In all conformers, the highest filled molecular orbital and the lowest (first) empty molecular orbital energy range corresponded to the state of $33 \rightarrow 34$ type, this corresponds to the HOMO-LUMO energy gap and is given in Figure 4. The lowest energy transition was observed in the case where the oscillator power is the lowest, that is, in the S1 state, and as a result of the calculations, this transition type was found to be HOMO-1-LUMO.

The HOMO-LUMO energy range corresponds to state S2 at T5CA_1, but this energy range corresponds to state S3 in the T5CA_3 conformer, and the percentage ratio is the greatest (0.69966). The result of this large energy range can be explained by the high degree of aromaticity of the molecule.

Table 3. TD-DFT calculated results of singlet states, types and percentages, relative energies, oscillator strengths and excitation energies for the optimized four conformers of the T5CA.

T5CA_1

\begin{tabular}{|c|c|c|c|c|c|}
\hline State & type & \% type & $\boldsymbol{\Delta E}(\mathrm{eV})$ & $f$ & $\boldsymbol{E}(\mathbf{n m})$ \\
\hline $\mathrm{S}_{0}$ & & & 0 & & \\
\hline $\mathrm{S}_{1}$ & $32 \rightarrow 34$ & 0.70145 & 4.4143 & 0.0000 & 280.87 \\
\hline $\mathrm{S}_{2}$ & $\mathbf{3 3} \rightarrow \mathbf{3 4}$ & $\mathbf{0 . 6 9 0 3 9}$ & $\mathbf{5 . 0 9 3 7}$ & $\mathbf{0 . 2 0 3 9}$ & $\mathbf{2 4 3 . 4 1}$ \\
\hline $\mathrm{S}_{3}$ & $30 \rightarrow 34$ & 0.68741 & 5.1127 & 0.0000 & 242.50 \\
\hline $\mathrm{S}_{4}$ & $31 \rightarrow 34$ & 0.67837 & 5.4598 & 0.0880 & 227.09 \\
\hline $\mathrm{S}_{5}$ & $33 \rightarrow 35$ & 0.61599 & 5.8157 & 0.0010 & 213.19 \\
\hline $\mathrm{S}_{6}$ & $32 \rightarrow 36$ & 0.67976 & 5.9319 & 0.0031 & 209.01 \\
\hline
\end{tabular}

T5CA_2

\begin{tabular}{|c|c|c|c|c|c|}
\hline State & type & \% type & $\boldsymbol{\Delta E}(\mathrm{eV})$ & $\boldsymbol{f}$ & $\boldsymbol{E}(\mathrm{nm})$ \\
\hline $\mathrm{S}_{0}$ & & & 0 & & \\
\hline $\mathrm{S}_{1}$ & $32 \rightarrow 34$ & 0.69208 & 4.4582 & 0.0000 & 266.63 \\
\hline $\mathrm{S}_{2}$ & $31 \rightarrow 34$ & 0.68920 & 4.7998 & 0.0000 & 258.31 \\
\hline $\mathrm{S}_{3}$ & $\mathbf{3 3} \rightarrow \mathbf{3 4}$ & $\mathbf{0 . 6 9 9 6 6}$ & $\mathbf{5 . 0 6 1 4}$ & $\mathbf{0 . 1 9 6 8}$ & $\mathbf{2 4 4 . 9 6}$ \\
\hline $\mathrm{S}_{4}$ & $30 \rightarrow 34$ & 0.67217 & 5.4973 & 0.0000 & 225.54 \\
\hline $\mathrm{S}_{5}$ & $33 \rightarrow 35$ & 0.63857 & 5.7689 & 0.0010 & 214.92 \\
\hline $\mathrm{S}_{6}$ & $32 \rightarrow 36$ & 0.69437 & 5.8764 & 0.0026 & 210.99 \\
\hline
\end{tabular}

T5CA_3

\begin{tabular}{|c|c|c|c|c|c|}
\hline State & type & \% type & $\boldsymbol{\Delta E}(\mathrm{eV})$ & $f$ & $\boldsymbol{E}(\mathbf{n m})$ \\
\hline $\mathrm{S}_{0}$ & & & 0 & & \\
\hline $\mathrm{S}_{1}$ & $32 \rightarrow 34$ & 0.68760 & 4.3587 & 0.0004 & 284.45 \\
\hline $\mathrm{S}_{2}$ & $30 \rightarrow 34$ & 0.59218 & 5.0910 & 0.0303 & 243.54 \\
\hline $\mathrm{S}_{3}$ & $\mathbf{3 3} \rightarrow \mathbf{3 4}$ & $\mathbf{0 . 6 2 5 0 7}$ & $\mathbf{5 . 2 0 3 5}$ & $\mathbf{0 . 1 5 6 2}$ & $\mathbf{2 3 8 . 2 7}$ \\
\hline $\mathrm{S}_{4}$ & $31 \rightarrow 34$ & 0.62965 & 5.5113 & 0.0661 & 224.96 \\
\hline $\mathrm{S}_{5}$ & $33 \rightarrow 36$ & 0.55993 & 5.7323 & 0.0014 & 216.29 \\
\hline $\mathrm{S}_{6}$ & $32 \rightarrow 35$ & 0.42201 & 5.9998 & 0.0035 & 206.65 \\
\hline
\end{tabular}

T5CA_4

\begin{tabular}{|c|c|c|c|c|c|}
\hline State & type & \% type & $\boldsymbol{\Delta E}(\mathrm{eV})$ & $f$ & $\boldsymbol{E}(\mathrm{nm})$ \\
\hline $\mathrm{S}_{\mathrm{o}}$ & & & 0 & & \\
\hline $\mathrm{S}_{1}$ & $32 \rightarrow 34$ & 0.66668 & 4.5580 & 0.0033 & 272.01 \\
\hline $\mathrm{S}_{2}$ & $31 \rightarrow 34$ & 0.68510 & 4.7644 & 0.0021 & 260.23 \\
\hline $\mathrm{S}_{3}$ & $\mathbf{3 3} \rightarrow \mathbf{3 4}$ & $\mathbf{0 . 6 4 7 8 8}$ & $\mathbf{5 . 0 9 2 9}$ & $\mathbf{0 . 1 6 0 9}$ & $\mathbf{2 4 3 . 4 4}$ \\
\hline $\mathrm{S}_{4}$ & $33 \rightarrow 35$ & 0.52394 & 5.4544 & 0.0343 & 227.31 \\
\hline $\mathrm{S}_{5}$ & $33 \rightarrow 35$ & 0.45243 & 5.5958 & 0.0418 & 221.56 \\
\hline $\mathrm{S}_{6}$ & $32 \rightarrow 35$ & 0.50715 & 5.6344 & 0.0061 & 220.05 \\
\hline
\end{tabular}

MEPs are a preferred study because they provide information about electrophilic attacks, because the single maxima of MEP are located only in the nuclei [13]. In T5CA (Figure 6), the regions with the most negative MEP indicate the most likely regions of electrophilic attack. From Figure 6, it is seen that the most negative region belongs to T5CA_3 conformer and this minimum value is $-7.618 \mathrm{e}-2$. It was 
observed in the carboxyl group on $\mathrm{O}$ bonded with a double bond to the $\mathrm{C}$ atom, and it can be said that the electrophilic attack is the most in this region. The most positive region is around the hydrogens of the carboxyl group and is seen as the blue region.
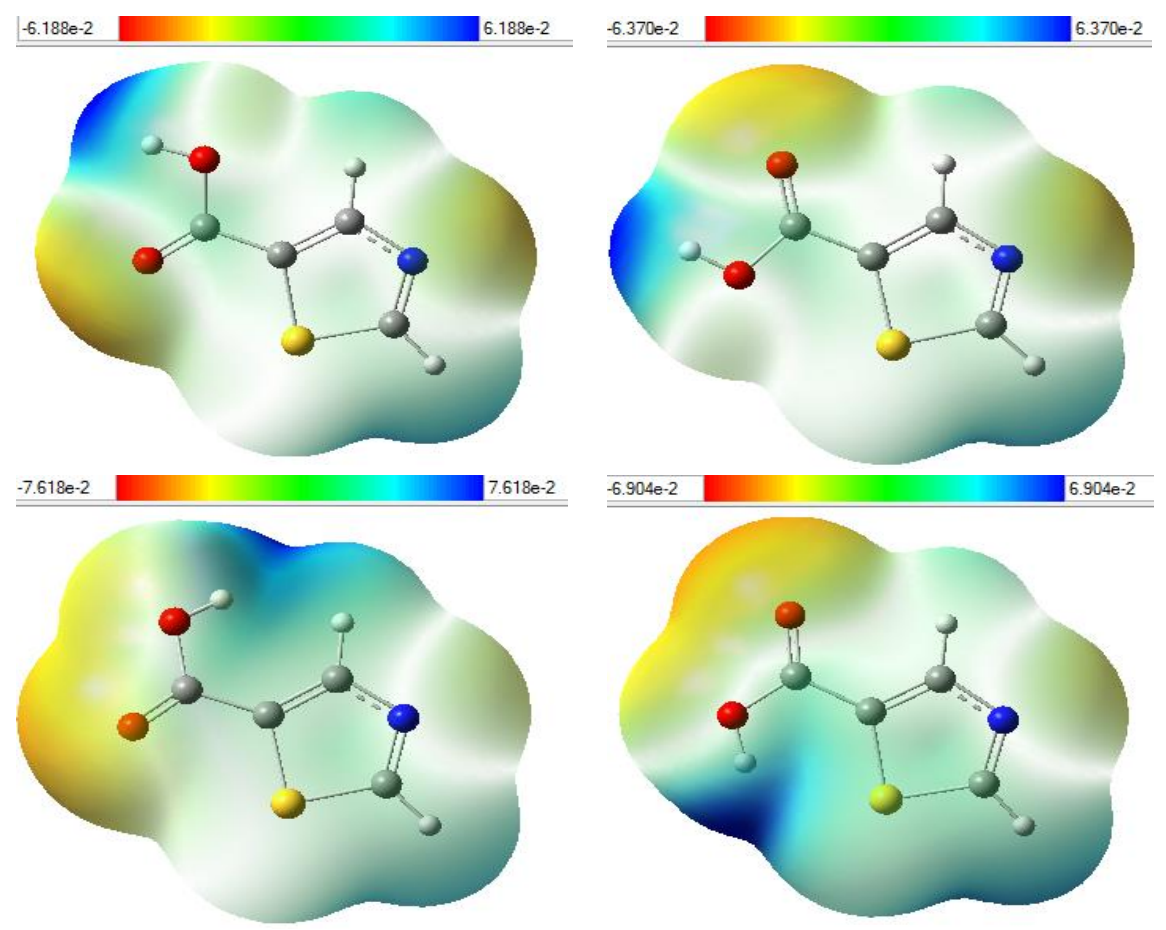

Figure 6. Molecular electrostatic potential (MEP) map for T5CA conformers calculated by DFT method using B3LYP/6-311++G(d,p) level.

Table 4. Natural and Mulliken charges of T5CA calculated using DFT method.

\begin{tabular}{|l|c|c|c|c|c|c|c|c|}
\hline \multirow{2}{*}{$\begin{array}{c}\text { Atom } \\
\text { No }\end{array}$} & \multicolumn{2}{|c|}{ T5CA_1 } & \multicolumn{2}{c|}{ T5CA_2 } & \multicolumn{2}{c|}{ T5CA_3 } & \multicolumn{2}{c|}{ T5CA_4 } \\
\cline { 2 - 9 } & Mulliken & Natural & Mulliken & Natural & Mulliken & Natural & Mulliken & Natural \\
\hline C1 & -0.406 & 0.033 & -0.491 & 0.040 & -0.499 & -0.001 & -0.463 & 0.036 \\
\hline N2 & -0.056 & -0.460 & -0.054 & -0.458 & -0.056 & -0.458 & -0.043 & -0.446 \\
\hline C3 & -0.106 & -0.099 & -0.155 & -0.098 & -0.085 & -0.100 & -0.116 & -0.084 \\
\hline S4 & -0.061 & 0.462 & -0.024 & 0.450 & -0.033 & 0.479 & -0.160 & 0.382 \\
\hline C5 & 0.378 & -0.351 & 0.384 & -0.355 & 0.684 & -0.357 & 0.670 & -0.358 \\
\hline H6 & 0.195 & 0.223 & 0.197 & 0.226 & 0.142 & 0.202 & 0.201 & 0.231 \\
\hline H7 & 0.252 & 0.212 & 0.246 & 0.212 & 0.253 & 0.214 & 0.255 & 0.215 \\
\hline C8 & -0.002 & $\mathbf{0 . 7 6 4}$ & 0.086 & $\mathbf{0 . 7 6 6}$ & -0.217 & $\mathbf{0 . 7 6 2}$ & -0.154 & $\mathbf{0 . 7 6 5}$ \\
\hline O9 & -0.296 & $\mathbf{- 0 . 5 8 9}$ & -0.299 & $\mathbf{- 0 . 5 8 4}$ & -0.272 & $\mathbf{- 0 . 5 5 1}$ & -0.271 & $\mathbf{- 0 . 5 4 6}$ \\
\hline O10 & -0.191 & $\mathbf{- 0 . 6 8 3}$ & -0.190 & $\mathbf{- 0 . 6 8 6}$ & -0.150 & $\mathbf{- 0 . 6 6 2}$ & -0.150 & $\mathbf{- 0 . 6 6 5}$ \\
\hline H11 & 0.294 & $\mathbf{0 . 4 8 8}$ & 0.299 & $\mathbf{0 . 4 8 8}$ & 0.232 & $\mathbf{0 . 4 7 1}$ & 0.231 & $\mathbf{0 . 4 7 0}$ \\
\hline
\end{tabular}

In addition to the analysis of the orbital interactions, the Mulliken and natural atomic charges of T5CA conformers were calculated using B3LYP level. These charges are given in Table 4. The chemical reactivities of each atom were determined and it was found that the atoms that provide the orbital interactions at the highest stabilization energy were the same atoms (C8, O9, O10 and H11), 
Electrophilic and nucleophilic regions were determined by analyzing the results in the Table 4 . The most negative charges of the structure are localized on $\mathrm{O} 9$ and $\mathrm{O} 10$ atoms, while the most positive charges are localized on $\mathrm{C} 8$ and $\mathrm{H} 11$ atoms.

\section{CONCLUSION}

T5CA optimized conformers investigated theoretically calculated by DFT method with (B3LYP)/6$311++\mathrm{G}(\mathrm{d}, \mathrm{p})$ level. Four conformers of T5CA were found to be related to the orientations of the carboxylic acid and hydroxyl groups. The most stable structure is the conformer called T5CA_1 in which the $\mathrm{OH}$ group is close to the $\mathrm{S}$ atom. According to NBO calculation results, the conformers with the highest stabilization energies were T5CA_1 and 2 and the corresponding to the highest stabilization energy was $\mathrm{LP}(2) \mathrm{O}-\pi^{*}(\mathrm{C} 8-\mathrm{O} 9)$ donor-acceptor orbital interactions. The HOMO-LUMO energy differences were found to be very close to each other for all conformers and these values were between 5.36 and $5.47 \mathrm{eV}$. According to the results of TD-DFT calculations, the highest value of oscillator strength was 0.2039 and it was observed in S2 singlet state in T5CA_1. From the MEP results, it was found that the region with the highest electron density is around the $\mathrm{O} 9$ atom. Positive regions were observed on H11, where the blue color is intense. Mulliken and natural atomic charges of T5CA conformers were calculated.

\section{REFERENCES}

[1] Kaur G, Singh JV, Gupta MK, Bhagat K, Gulati HK, SinghA, Bedi PMS, Singh H and Sharma S. Thiazole-5-carboxylic acid derivatives as potent xanthine oxidase inhibitors: design, synthesis, in vitro evaluation, and molecular modeling studies. Medicinal Chemistry Research 2020; 29, 8393.

[2] Halasa A, Reva I, Lapinski L, Nowak MJ and Fausto R. Conformational Changes in Thiazole-2carboxylic Acid Selectively Induced by Excitation with Narrowband Near-IR and UV Light. J. Phys. Chem. A 2016; 120, 13, 2078-2088.

[3] Schneider JMFM., Sales ES, Livotto PR, Schneider PH, Merlo AA. Synthesis of new family of thiazoline and thiazole esters and investigation of their thermal properties. J. Braz. Chem. Soc. $2014 ; 25,8,1493-1503$.

[4] Meundaeng N, Rujiwatra A, Prior JT. Polymorphism in metal complexes of thiazole-4-carboxylic acid. Transition Metal Chemistry 2016; 41, 783-793.

[5] Li H, Kennedy SD, Goldstein BM. Solid-state and solution conformations of isotiazofurin: crystallographic, computational and 1H NMR studies. Acta Crystallogr B. 1993; 1;49 (Pt 4):72938 .

[6] Bonnel C, Legrand B, Bantignies J-L., Petitjean H, Martinez J, Masurier N and Maillard LT. FTIR and NMR structural markers for thiazole-based $\gamma$-peptide foldamers. Organic \& Biomolecular Chemistry 2016; 14, 8664-8669.

[7] Frisch MJ et al. Gaussian 09, Revision A.0.2, Gaussian, Inc., Wallingford CT, 2009.

[8] Reed AE, Curtiss LA, Weinhold F. Intermolecular interactions from a natural bond orbital, donoracceptor viewpoint. Chem. Rev. 1988; 88, 899-926. 
[9] Bauernschmitt R, Ahlrichs R. Treatment of electronic excitations within the adiabatic approximation of time dependent density functional theory. Chem. Phys. Lett. 1996; 256, 454464.

[10] Stratmann RE, Scuseria GE, Frisch MJ. An efficient implementation of time-dependent densityfunctional theory for the calculation of excitation energies of large molecules. J. Chem. Phys. $1998 ; 109,8218-8224$.

[11] Miyagawa M, Akai N, Nakata M. UV-Light Induced Conformational Changes of 2Pyridinecarboxylic Acid Isolated in Low-Temperature Argon Matrices. J. Mol. Struct. 2015; $1086,1-7$.

[12] Weinhold F, Landis CR. Valency and Bonding. A Natural Bond Orbital Donor-Acceptor Perspective. Cambridge University Press: New York, 2005.

[13] Alcamí M, Mó O, Yáñez M. Modelling Intrinsic Basicities: The Use of the Electrostatic Potentials and the Atoms-in-Molecules Theory. Theor. Comput. Chem. 1996; 3, 407-456. 